\title{
A review of the success of major crane conservation techniques
}

\author{
CARMEN DAVIS
}

\section{Summary}

The purpose of this paper is to review the success of different crane conservation techniques in order to determine which combinations of techniques are most promising. Six major crane conservation techniques were defined and a literature review was conducted. A summary of each technique was prepared, including several examples of the technique's use and possible negative effects. All of the evaluated techniques were successful in at least some cases. Habitat and legal protection are general measures that are required for every species regardless of other conservation techniques being used. Artificial feeding is successful in rapidly bolstering some crane populations but may not be desirable as a long-term conservation technique. Powerline modification or removal should be used to preserve all localized or endangered crane populations. The release of captive-reared cranes shows promise as a conservation technique but should only be used as a last resort. Likewise, manipulation of wild crane eggs should only be used when absolutely necessary to establish or bolster captive flocks.

\section{Introduction}

Cranes are among the most endangered birds in the world. Seven of the 15 crane species are officially listed as Threatened or Endangered under the IUCN Red List Categories system; four more are proposed for listing (Meine and Archibald 1996). Crane conservation techniques include legal protection, habitat protection, artificial feeding, manipulation of wild crane eggs, powerline modification and captive releases. Not every technique will work in every case and conservation resources are limited. Therefore, resources need to be directed toward the combination of techniques that is most appropriate for each crane population. In order to do this, an evaluation of the relative success of different conservation techniques is needed. There have been at least two previous discussions of crane conservation techniques (Archibald and Mirande 1985, Meine and Archibald 1996). This paper builds on these by summarizing the success of different techniques and by suggesting which combinations of techniques show the most promise for crane conservation.

\section{Methods}

Not all crane conservation techniques were evaluated. The techniques chosen were those that are most easily quantified and have been used among a variety of crane species. A literature review was conducted for each technique. The time 
frame over which a technique was used and how the crane population numbers changed during that time period were examined. In many cases mortality statistics, breeding statistics and evidence of adaptive behaviour were also used to judge the relative success of a technique. The time-scale over which a technique is effective was also considered. Some techniques provide rapid results that may only be sustainable for a short time; others may take a while to work but may be more sustainable in the long run.

\section{Results and discussion}

\section{Legal protection}

For the purpose of this evaluation, legal protection is defined as laws that prohibit or limit crane hunting. Crane hunting laws have historically been enacted only after crane populations have experienced drastic declines. Examples include the Whooping Crane Grus americana, Red-crowned Crane G. japonensis in Japan and the central flock of Siberian Cranes G. leucogeranus.

The North-West Frontier Province of Pakistan banned the hunting of Siberian Cranes in 1984 and outlawed the capture of other crane species outside specific hunting seasons (UNEP/CMS 1995). Hunting-camp fees, crane-possession fees and crane-export fees were also adopted to control hunting (UNEP/CMS 1995). These laws were not well received because a strong crane-hunting tradition exists and hunters felt that their willingness to cooperate in a hunting survey had been used against them. Laws were enacted after the survey revealed that hunting pressure was increasing, while wild crane populations were decreasing (UNEP/ CMS 1995). However, the shooting of Siberian Cranes in Pakistan is not well documented and few of the hunters surveyed reported ever having seen one (Landfried et al. 1995).

The number of Siberian Cranes wintering at Keoladeo National Park in India declined from 200 in 1964-1965 (Walkinshaw 1973) to only three individuals in 1996-1997 (ICF 1997). These results suggest that hunting laws were enacted too late to save the central flock of Siberian Cranes. However, hunting legislation, in addition to hunter education and captive breeding programmes, should be able to prevent similar declines among the Eurasian G. grus and Demoiselle Cranes Anthropoides virgo that still migrate through Pakistan in large numbers.

Despite the Migratory Bird Treaty Act of 1916, the population of migrant Whooping Cranes in North America declined from 70 in 1916 to only 14 in 1941 (Allen 1952). Less than half of the 39 known adult mortalities between 1938-1949 were estimated to be due to natural causes (Allen 1952). In contrast, since 1968 only four Whooping Cranes are known to have been shot (Kuyt 1992). These figures suggest that hunting laws were effective once they were combined with increased public education throughout the migratory flyway.

The hunting of Red-crowned Cranes in Japan was not specifically prohibited until 1889 when their numbers had already drastically declined due to hunting (Inouye 1981). Hunting at Kushiro Marsh in Hokkaido was not prohibited until 1925, when a flock of less than 20 Red-crowned Cranes was discovered (Inouye 1981). Despite this protection, the population at Kushiro did not rise above 35 birds until a feeding station was established in 1952 (Masatomi 1981). In this 
case, the hunting law prevented any further declines in an already small crane population.

The migratory subspecies of the Sandhill Crane G. canadensis made a dramatic population recovery when crane hunting was banned in the United States (Archibald and Mirande 1985). Legal Sandhill Crane hunts are now conducted in several states and populations are monitored to assess the impact of legal hunting (Sharp 1995). The crane hunting seasons are also carefully managed to minimize the threat to migrating Whooping Cranes (Lewis 1992).

Legal protection is a basic conservation measure that should be provided for all crane species. As shown by the example of the Whooping and Siberian Cranes, uncontrolled hunting can have devastating effects on populations. Therefore, hunting of any crane population, no matter how large, should be carefully monitored. Although it was not evaluated as a conservation technique, education is recognized as a vital part of any attempt to enforce legal protection.

\section{Habitat protection}

Habitat protection includes the establishment of formal preserves and the long-term management of those preserves as part of larger ecosystems. Habitat protection also includes the management of private lands to accomodate cranes and people.

China is a good example of the challenge that formal habitat protection poses for countries throughout the world. Thirty-two nature reserves in China have been established primarily for cranes. An estimated 25,500-31,800 individuals of seven crane species use these reserves based on aerial and ground surveys and literature reviews (Yiqing and Xiaomin 1994). From these numbers, it is obvious that the establishment of preserves has been an effective conservation technique. However, the development of industry and agriculture, and chemical pollution are serious threats to protected areas in China (Fuyun 1994). These problems emphasize the importance of not only establishing preserves but also enforcing their protected status to ensure long-term security. This means balancing the needs of cranes with those of a growing human population and managing preserves as part of a larger ecosystem. Fortunately, many crane species have also demonstrated the ability to adapt to habitats modified by humans.

Black-necked Cranes G. nigricollis wintering in the Sangti Valley of India (Gole 1996) and the Phobjikha Valley of Bhutan (Caron 1994) feed on waste grain in agricultural fields. The expansion of agriculture has allowed the Blue Crane $A$. paradiseus to colonize new areas (Allan 1995). The population increase of the Eurasian Crane in Sweden has been attributed to increased use of agricultural areas for feeding and nesting (Bylin 1987). A water restoration project, in combination with an artificial feeding area, at Lake Hornborga in Sweden has resulted in increased numbers of migrating and nesting Eurasian Cranes there. The number of nesting pairs at the lake increased from zero in the early 1970s to as many as seven in 1982 (Swanberg 1987).

Cranes have also adapted to using smaller wetlands when there is sufficient food available. A study of migrating Whooping Cranes revealed that over $40 \%$ of wetlands used for roosting were less than 0.5 ha (Howe 1989) and $56 \%$ of feeding sites were less than $1 \mathrm{~km}$ from the roosting sites (Howe 1987). Small 
wetlands associated with croplands have also been important in the population recovery of the Sandhill Crane (Harris and Barzen 1996). Siberian Cranes wintering in Iran take advantage of artificial water impoundments (Ashtiani 1987).

Use of private land can also bring cranes into conflict with humans. When cranes feed in agricultural areas they may be intentionally or inadvertently poisoned. Close contact with humans can also increase the hunting threat to cranes. Obviously, private lands are not secure as crane habitat over the long term. Economic pressures can result in the development of private lands, making them unsuitable for cranes. Therefore, the use of private property by cranes should not overshadow the need to maintain protected areas. As with legal protection, education is important in efforts to establish formal protected areas and to preserve private lands as crane habitat.

\section{Artificial feeding}

Artificial feeding may include: feeding stations, where grain is spread on the ground; food crops planted specifically for cranes; artificial water impoundments stocked with aquatic life; and land-management techniques that make food more readily available to cranes. Feeding stations are primarily established for wintering cranes but the benefits are likely to carry over into the breeding season. Other artificial feeding techniques may be used during the breeding season.

A feeding station for Red-crowned Cranes was established in Hokkaido, Japan in 1952. The mean number of cranes using the site increased from 42 in 19521954 to 161 in $1960-1964$ (Masatomi 1991). The rate of increase over the previous five-year period was $65.8 \%$ in 1960-1964 (Masatomi 1991). Six hundred Red-crowned Cranes were counted in the winter of 1993-1994 (Kushiro ECRPT 1993). Masatomi (1991) attributes population growth to the increased winter survival that resulted from the feeding programme.

Artificial feeding of White-naped $G$. vipio and Hooded G. monachus Cranes at Izumi, Japan began in 1962. A significant relationship was found between the rate of population increase for Hooded Cranes and the availability of food the previous winter (Ohsako 1994). The number of Hooded Cranes increased from about 800 in 1962-1963 to more than 8,000 in 1992-1993 (Ohsako 1994). No significant correlation was found for White-naped Cranes, although their numbers did increase from less than 100 in 1962-1963 to over 2,000 in 1992-1993 (Ohsako 1994).

The villagers of Khichan, India established an artificial feeding area for Demoiselle Cranes in 1984. The number of cranes has increased from 200 prior to 1984 to nearly 6,000 in 1995 (Jain 1995).

In 1980, an artificial feeding station for Eurasian Cranes was established at Lake Hornborga in Sweden. The agricultural activity that had traditionally attracted cranes was halted in 1972 and crane numbers had decreased since that time. Flock sizes increased from 750 cranes a day in 1979 (Swanberg 1987) to 5,000 in 1995 (Traneving 1997).

During the 1960s at Aransas National Wildlife Refuge, grain was spread in enclosures and an artificial water impoundment was stocked with aquatic life. These feeding areas were visited by groups of up to 34 Whooping Cranes 
(Johnson 1976). Controlled burns have also been used to increase winter food availability. In years of good acorn production, flocks of up to 28 cranes have been observed at upland burn sites (J. Lewis 1993, unpublished). There is no proof that feeding areas or controlled burns have positively influenced Whooping Crane population growth. However, a recent study suggests that differential reproductive success between the springs of 1993 and 1994 may have been linked to food availability during the previous winter (Chavez-Ramirez 1996).

Increased winter food supplies are also believed to increase the breeding success of the Hooded Cranes which winter at Izumi (Ohsako 1994). Modification of crane behaviour is another possible benefit of artificial feeding. Feeding appears to result in "tamer" cranes; cranes fed in heavily populated areas have shown the ability to tolerate human disturbance (Archibald 1978). This trait may benefit the cranes' survival as human populations continue to increase. Unfortunately, "tame" cranes may also be intentionally harmed by humans.

Other negative effects of artificial feeding include increased disease risk and human disturbance. Increased disease risk can result from overcrowding or from tainted food supplies. Overcrowding can be temporarily reduced by dispersing cranes among several feeding stations. The quality of food provided at feeding stations should be carefully monitored to make sure it is safe. Excessive human disturbance at feeding stations can be eliminated by use the of observation blinds, construction of visual barriers, and increased public education.

Artificial feeding can produce dramatic results; small crane populations can increase quickly when artificial feeding is in place. However, due to the negative effects mentioned above, positive results may not be sustainable in the long term. Therefore, artificial feeding should be viewed as a short-term method of bolstering crane numbers until other permanent conservation measures are in place.

\section{Manipulation of wild crane eggs}

Manipulation of wild eggs includes removal of second eggs, field-testing of egg viability and switches of captive and wild eggs. The second egg laid in some crane species is rarely reared because of sibling aggression. Direct benefits have included the establishment of captive flocks, increased genetic diversity of captive flocks and increased hatching. success of wild eggs. Most crane reintroduction efforts rely heavily on the presence of captive flocks as a source of eggs and chicks.

Captive breeding flocks of Whooping and Mississippi Sandhill Cranes G. $c$. pulla were established by the removal of second eggs from wild nests. Between 1981 and 1992, 167 captive-reared birds were released at the Mississippi Sandhill Crane National Wildlife Refuge (Seal and Hereford 1992). From 1967 to 1988 there was an initial net world population gain of 93 fledged Whooping Cranes from the Wood Buffalo flock (J. Lewis 1988, unpublished). By June 1996, 100 captive-reared Whooping Cranes had been released in Florida's Kissimmee Prairie (S. Nesbitt 1996, unpublished). Some of the chicks released in Florida have come from wild eggs, but captive flocks are expected to provide all chicks for future releases. 
Egg removals and switches have allowed captive facilities to increase the genetic diversity of their flocks with minimal impact on the productivity of wild populations. Whooping Crane eggs have been removed from Wood Buffalo nesting territories that are under-represented in the captive flock. White-naped and Red-crowned Crane eggs in Russia's Khinganski Nature Reserve are switched with surplus captive eggs from North American breeding facilities.

Since 1985, Whooping Crane eggs have been tested for viability so that at least one viable egg is left in each Wood Buffalo nest. The hatching success of tested and untested eggs was compared during the period 1985-1988. The hatching success of viable single eggs placed in nests was $11.7-15.5 \%$ greater than that of untested eggs (Kuyt 1996). The Wood Buffalo population has increased despite the removal of eggs and without the addition of captive-reared birds. Although egg removals have not been proven to affect nest success negatively (Mirande et al. 1993), they should be discontinued once they are no longer necessary.

\section{Modification or removal of powerlines}

Powerlines may be removed, re-routed or modified to decrease crane mortality. Modification is defined as the attachment of visual markers to the lines. Markers may include swinging plates, colored aviation balls or spiral vibration dampers.

In the early 1970s, powerlines in Hokkaido, Japan were marked, buried or removed. Between 1970-1974 and 1980-1984 the percentage of known mortalities due to collisions decreased from $70.9 \%$ to $26.8 \%$ (Masatomi 1991). The mean rate of increase over the previous five-year period rose from 5.9\% in 1970-1974 to $38.9 \%$ in $1980-1984$ (Masatomi 1991). The percentage of juveniles and the number of breeding pairs in the population has also increased (Masatomi and Momose 1995).

Powerlines at two North American migration stopovers were marked to reduce Sandhill Crane collision mortality. Swinging metal plates reduced crane and waterfowl collision mortality by $63 \%$ at Monte Vista National Wildlife Refuge, Colorado (Brown and Drewien 1995). Spiral vibration dampers reduced collision mortality by 61\% (Brown and Drewien 1995). Yellow aviation balls significantly reduced Sandhill Crane collision mortality near the Platte River in Nebraska (Morkill and Anderson 1990).

The best way to minimize collisions is to avoid routing powerlines through sensitive crane habitat. For example, construction of the Ariadne-Venus $400 \mathrm{kV}$ transmission line in South Africa was expected to affect Blue Crane, Grey Crowned Crane Balearica regulorum and Wattled Crane Bugeranus carunculatus populations. In order to select the route least detrimental to these species, crane movement patterns were studied and extinction risk was determined for each possible route (McCann and Wilkins 1995).

These results indicate that modification or removal of powerlines are worthwhile conservation techniques. They are effective in reducing mortality in localized and endangered crane populations and they are sustainable over the long term.

\section{Release of captive-reared birds}

Captive-reared cranes may be released into existing wild populations or they may be reintroduced into parts of their former range. Releases of captive-reared 
birds have been conducted for Siberian, Whooping, Red-crowned, White-naped and Sandhill Cranes. The Siberian Crane reintroduction programme has been unsuccessful in bolstering the number of birds in the central flock. None of the captive-reared, released birds have been seen after initiating migration (Sorokin 1995). Problems have included high chick mortality during rearing, poaching of released birds and a lack of wild conspecifics to guide the released birds (Sorokin 1995).

The establishment of a non-migratory flock of Whooping Cranes in Florida has met with preliminary success. For the 1995 releases, first-year mortality was down to $52.6 \%$ from an average of $66.4 \%$ for the $1993-1994$ releases (S. Nesbitt 1996, unpublished). First-year survival was up to $71.4 \%$ for the 1996 releases (S. Nesbitt 1996 unpublished). This drop in mortality is credited to the use of better release sites and the presence of previously released Whooping Cranes. Four-year old Whooping Cranes have been observed defending a territory, nest-building and copulating (S. Nesbitt 1996, unpublished). However, a recent population viability assessment suggests that even in a best-estimate scenario, population growth will be slow or negative once releases stop (Mirande and Cannon 1996).

Releases of Mississippi Sandhill Cranes have been successful in terms of survival and pairing. In 1992, the overall first-year survival of released birds was $70 \%$ and adult survival was $91.3 \%$ (Seal and Hereford 1992). Captive-reared birds represented $80 \%$ of the wild population in 1992 and $60 \%$ of known breeding pairs consisted of at least one captive-reared bird (Seal and Hereford 1992). In 1996 there were 13 nesting pairs in the wild; the most counted since censusing began in 1983 (S. Hereford 1996, unpublished). Recruitment in this population continues to be below replacement level, but it is possible that the releases are at least helping the population to remain viable. In any case, the causes for low recruitment must be identified since supplementation cannot continue indefinitely.

Releases of semi-wild Red-crowned and White-naped Cranes in Khinganski Nature Reserve have met with some success. By the summer 1995, four of the 10 released birds were migrating and returning in the spring, and one pair of semi-wild cranes had nested successfully for the past four years (L. Leindecker 1995, unpublished). A semi-wild female and wild male were observed defending a human-disturbed territory outside the reserve; this pair migrated and returned to their territory the following spring (Andronov and Andronova 1995). This release is unique because it does not aim only to bolster crane numbers. It is also an attempt to modify the behaviour of an existing population so that more breeding habitat is available to them.

Experimental migratory releases of Sandhill Cranes into a flock of wild cranes have been successful. Of the 38 Greater Sandhill Crane G. c. tabida chicks released at Seney National Wildlife Refuge in 1988-1990, at least $84 \%$ survived for one year after release (Urbanek and Bookhout 1994). A minimum of $74 \%$ of both males and females returned to Upper Michigan (Urbanek and Bookhout 1994). In 1993, at least four captive-reared males nested with wild mates, and chicks hatched from two nests (Urbanek and Bookhout 1994).

Establishment or supplementation of non-migratory crane populations shows promise, while migratory releases have achieved success only when birds were released into an existing flock. Since this is not possible for species such as the Siberian and Whooping Crane, a method using ultralight aircraft is being 
developed for use in these instances. Captive-reared cranes can be taught a migration route by releasing them on the breeding ground and leading them to an appropriate wintering area (Clegg et al. 1996).

Since releases consume large amounts of time and resources, they require extensive planning and constant re-evaluation. Population modelling should be conducted in advance to determine how many birds need to be released in order to establish a self-sustaining population or bolster an existing population. Once the release is under way and new information becomes available, the model should be updated. The release can then be modified, if necessary, to improve the probability of success.

Monitoring of released birds is also imperative, as shown by the Florida Whooping Crane reintroduction. Each released Whooping Crane is radio-tracked daily for one year and then weekly thereafter. This high level of monitoring has allowed biologists to identify causes of mortality and watch for evidence of breeding among released birds. In contrast, due to lack of satellite tracking equipment, the fate of released Siberian Cranes is not known once they leave on migration. The knowledge that could be gained from tracking would be invaluable for evaluating the release.

Although several releases have been promising in various respects, no self-sustaining population of cranes has been established through reintroduction. Although it is hoped that reintroduction will serve as a long-term conservation measure, captive releases do not yield rapid results. The final outcome of most of these releases will not be known for many years, so evaluation of this technique is ongoing.

\section{Conclusion}

All of the evaluated conservation techniques have proven to be successful in at least some instances. The most successful crane conservation plans will utilize a combination of these techniques. Legal protection and habitat protection are basic conservation measures that are required for every crane species. Education, though not discussed here as a conservation technique, should be closely tied to all efforts to protect cranes and their habitat.

Artificial feeding should not be relied upon as a long-term conservation technique. It should be used to help increase small crane populations but conservation efforts should also ensure that there is sufficient habitat to sustain a growing population. Public education and powerline modification should also be used at artificial feeding stations. Plans should be in place to decide at what point further population growth is no longer desirable.

Removal and modification of powerlines should be specifically used for localized and endangered crane populations. These techniques are sustainable over the long term and can be used in addition to other techniques.

Egg manipulations should only be used as necessary to establish or maintain viable captive populations. Releases of captive-reared birds should be used as a last resort for preserving endangered crane populations. Habitat and legal protection must be in place if a reintroduced population is expected to eventually be self-sustaining. Artificial feeding and powerline modification may also be useful as part of a reintroduction programme. 


\section{Acknowledgements}

Thanks to Scott Swengel for the initial idea to write the paper and for help in finding literature. Thanks to Scott Swengel and Dr Julie Langenberg for comments that improved the manuscript.

\section{References}

Allan, D. G. (1995) Habitat selection by Blue Cranes in the Western Cape Province and the Karoo. S. Afr. J. Wildl. Res. 25(3).

Allen, R. P. (1952) The Whooping Crane. New York: National Audubon Society (Research rep. 3).

Andronov, V. A. and Andronova, R. (1995) Results and prospects of the activities of the centre of rare crane species in the Amur region. Crane Res. Protect. Eur. 37.

Archibald, G. W. (1978) Winter feeding programs for cranes. IV. Supplemental feeding. Pp. ${ }_{141-148}$ in Temple, S. A., ed. Endangered birds: management techniques for preserving threatened species. Madison, Wisconsin: University of Wisconsin Press.

Archibald, G. W. and Mirande, C. (1985) Population status and management efforts for endangered cranes. Trans. North Am. Wildl. Nat. Res. Conf. 50: 586-602.

Ashtiani, M. A. (1987) Siberian Crane as a wintering bird in Iran. Proc. 1983 Internatn. Crane Workshop. Baraboo, WI.

Brown, W. M. and Drewien, R. C. (1995) Evaluation of two powerline markers to reduce crane and waterfowl collisions. Wildl. Soc. Bull. 23: 217-227.

Bylin, K. (1987) The Common Crane in Sweden: distribution, numerical status, habitats, breeding success and need of protection. Proc. 1983 Internatn. Crane Workshop. 215223. Baraboo, WI.

Caron, C. (1994) Overlapping sanctuaries: complementary land utilization pattern among human beings and Black-necked Crane (Grus nigricollis) in the Phobjikha valley. Hanover, New Hampshire: Institute of Current World Affairs.

Chavez-Ramirez, F. (1996) Food availability, foraging ecology, and energetics of Whooping Cranes wintering in Texas. Ph.D. dissertation. Texas A\&M University.

Clegg, K. R., Lewis, J. C. and Ellis, D. H. (1997) Use of ultralight aircraft for introducing migratory crane populations. Proc. Seventh North Am. Crane Workshop, Baraboo, WI, 105113 .

Fuyun, Z. (1994) Conservation of wetlands and cranes in China. The future of cranes and wetlands. Tokyo: Wild Bird Society of Japan: 130-135.

Gole, P. (1996) Environment and ornithology in India. Jaipur, India: Rawat Publications.

Harris, J. and Barzen, J. (1996) Cranes on the farm. The ICF Bugle. 22(3).

Howe, M. (1987) Habitat use by migrating Whooping Cranes in the Aransas-Wood Buffalo corridor. Proc. 1985 Crane Workshop. Grand Island, NE: 303-311.

Howe, M. A. (1989) Migration of radio-marked Whooping Cranes from the Aransas-Wood Buffalo Population: patterns of use, behavior and survival. Washington, D.C.: U.S. Dept. of the Interior. (USFWS Techn. Rep. 21).

Inouye, M. (1981) A historical review of conservation of Red-crowned Crane (Tancho) in Hokkaido. Crane Research around the World. Baraboo, WI: International Crane Foundation: 99-101.

International Crane Foundation (ICF). (1997) Siberian Cranes in Iran and India. ICF Bugle. $23(1)$.

Jain, P. (1995) The Crane feeding station at Khichan. The ICF Bugle. 21(4).

Johnson, F. E. (1976) Aransas Whooping Cranes. Blue Jay. 34: 220-228.

Kushiro ECRPT (Editorial Committee on a Report on the Protection of Tancho). (1993) A report on the protection of Tancho, a special natural monument. Kushiro, Japan: Kushiro Department of City Development. 
Kuyt, E. (1992) Aerial radio-tracking of Whooping Cranes migrating between Wood Buffalo National Park and Aransas National Wildlife Refuge, 1981-1984. Ottawa: Canadian Wildlife Service (Occasional paper 74).

Kuyt, E. (1996) Reproductive manipulation in the Whooping Crane Grus americana. Bird Conserv. Internatn. 6:3-10.

Landfried, S. E., Chaudry, A. A., Malik, M. M., and Ahmad, A. (1995) Integrated crane conservation activities in Pakistan: education, research, and public relations. Pp. 121155 in Jacobson, S., ed. Conserving wildlife: international education and communication approaches. New York: Columbia University Press.

Lewis, J. (1992) The contingency plan for federal-state cooperative protection of Whooping Cranes. Proc. 1988 North Am. Crane Workshop. Talahassee, FL: Florida Game and Freshwater Fish Commission: 295-299.

Masatomi, H. (1981) The Red-crowned Crane. Crane Research around the World. Baraboo, WI: ICF: 81-85.

Masatomi, H. (1991) Population dynamics of Red-crowned Cranes in Hokkaido since the 1950s. Proc. 1987 Internatn. Crane Workshop. Baraboo, WI: ICF: 297-299.

Masatomi, H. and Momose, K. (1995) The status of the Tancho, or Red-crowned Crane, in Hokkaido, Japan. Cranes and storks of the Amur River. Moscow: Arts Literature Publ.: $40-41$.

McCann, K. and Wilkins, H. (1995) A study of the annual biology and movement patterns of the three crane species in the Kwazulu-Natal midlands; for the purpose of aiding the selection of the route for the Ariadne-Venus $400 \mathrm{kV}$ transmission powerline. Eskom and Endangered Wildlife Trust.

Meine, C. D. and Archibald, G. W. (eds) (1996) The cranes: status survey and conservation action plan. Gland, Switzerland: IUCN.

Mirande, C. and Cannon, J. (1997) Computer simulations of possible futures for two flocks of Whooping Cranes. Proc. Seventh North Am. Crane Workshop. Baraboo, WI: 181-197.

Mirande, C., Lacy, R. and Seal, U. (1993) Whooping Crane (Grus americana) conservation viability assessment workshop report. Apple Valley, Minnesota: IUCN/SSC Captive Breeding Specialist Group.

Morkill, A. E. and Anderson, S. H. (1990) Effectiveness of marking powerlines to reduce Sandhill Crane collisions. Laramie: Wyoming Cooperative Fish and Wildlife Reseach Unit.

Ohsako, Y. (1994) Analysis of crane population change, habitat selection and human disturbance in Japan. The future of cranes and wetlands. Tokyo: Wild Bird Society of Japan: $107-113$.

Seal, U. S. and Hereford, S. (1992) Mississippi Sandhill Crane (Grus canadensis pulla): population and habitat viability assessment workshop report. Apple Valley, Minnesota: IUCN/SSC Captive Breeding Specialist Group.

Sharp, D. E. (1995) Status and harvests of the mid-continent and Rocky Mountain populations of Sandhill Cranes, 1995. Golden, Colorado: Office of Migratory Bird Management, USFWS.

Sorokin, A. G. (1995) Project "Sterkh": restoration of the western and central populations of the Siberian Crane, annual report 1995. Moscow: All Russia Institute for Nature Conservation, Ministry of Ecology.

Swanberg, O. (1987) Migrating Common Crane in Sweden: experiments in farming for cranes and vegetation control in wetlands. Proc. 1983 Internatn. Crane Workshop. Baraboo, WI: ICF, 225-229.

Traneving, B. (1997) Lake Hornborga, a big tourist attraction in Sweden. The ICF Bugle. $23(1)$.

United Nations Environment Programme (UNEP)/Convention on the conservation of migratory species of wild animals (CMS). (1995) Memorandum of understanding concerning conservation measures for the Siberian Crane: report of the first meeting of range 
states. Bonn, Germany: Secretariat of the Convention on the Conservation of Migratory Species of Wild Animals.

Urbanek, R. P. and Bookhout, T. C. (1994) Performance of captive-reared cranes released into a migration route in eastern North America. The future of cranes and wetlands. Tokyo: Wild Bird Society of Japan: 121-129.

Walkinshaw, L. H. (1973) Cranes of the world. New York: Winchester Press.

Yiqing, M. and Xiaomin, L. (1994) The population and habitat of cranes in China's nature reserves. The future of cranes and wetlands. Tokyo: Wild Bird Society of Japan, 141-145.

\section{CARMEN DAVIS}

International Crane Foundation, P.O. Box 447, E-11376 Shady Lane Road, Baraboo, WI 53913-0447 U.S.A.

Correspondence to: 3601 Main Street NE, Blaine, MN 55449-6506 U.S.A. 